\title{
Семенной картофель при летних сроках посадки
}

\section{Н.К. Дубровин, Т.В. Боева, Г.Н. Киселева}

На основании результатов исследований в условиях дельты Волги на шести отечественных перспективных сортах: Вершининский, Жанна, Евгения, Валентина, Кисловодский и Волжанин (контроль), впервые установлен оптимальный срок летней посадки картофеля - III декада июля с густотой стояния растений от 54,9 до 71,4 тыс/га, обеспечивающий получение высококачественного семенного материала.

Ключевые слова: картофель, сроки посадки, густота стояния, сорта, семенная фракция.

A страханский картофель - сегодня такой же бренд, как астраханский арбуз и томат. Астраханская область обеспечивает полностью не только свои внутренние потребности (220 тыс. т), но и поставляет более 100 тыс. т раннего картофеля в другие регионы Российской Федерации [1].

Одна из приоритетных задач развития картофелеводства для региона - обеспечение сельхозпроизводителей качественным семенным материалом. Для получения семенного материала картофеля в дельте Волги лучше всего подходят летние посадки, так как клубнеобразование уходит от экстремально высоких температур воздуха и почвы. Решить задачу определения лучшего срока посадки для получения наибольшего количества клубней семенной фрак- ции от картофеля, актуально для этого региона.

Цель исследований: установить оптимальный летний срок и густоту стояния растений для получения семенной фракции картофеля, выращенного на безвирусной основе в почвенно-климатических условиях дельты Волги.

Исследования проводили на семенном картофеле класса элита, выращенного в ООО ЭТК «Меристемные культуры» предгорной зоне Ставропольского края. Перед посадкой клубни яровизировали в течение месяца при температуре $16{ }^{\circ} \mathrm{C}$ и высаживали в три срока: 1 срок (III декада июня), 2 срок (III декада июля), 3 срок (I декада августа). Картофель размещали с густотой стояния 54,9 тыс. раст/га (1,40× 0,13 м) и 71,4 тыс. раст/га $(1,40 \times 0,10$ м). Опыт закладывали в четырех пов- торностях на аллювиально-луговых почвах в 2014-2016 годах. Площадь делянки - 25,2 м². Размещение делянок в опыте - по методу случайных блоков. Агротехника - общепринятая для зоны Нижнего Поволжья, орошение с помощью капельного полива. Полевые опыты закладывали в соответствии с методикой опытного дела [2]; методическими указаниями по учету и контролю важнейших показателей процессов фотосинтетической деятельности растений в посадках [3]; методикой физиологических исследований в овощеводстве и бахчеводстве [4]; методикой исследований по культуре картофеля [5]. Данные результатов исследований обработаны методом дисперсионного анализа по Б.А. Доспехову с использованием компьютерных программ (Microsoft Office Excel 2007).

В результате исследований установлено, что на первом сроке посадки всходы картофеля появились в середине июля. Раньше всех они отмечены у сортов Жанна и Волжанин.

Нами установлено, что растения сортов картофеля при густоте 71,4 тыс. раст/га $(1,40 \times 0,10 \mathrm{M})$, раньше взошли и отличались лучшей полевой всхожестью, за исключени-

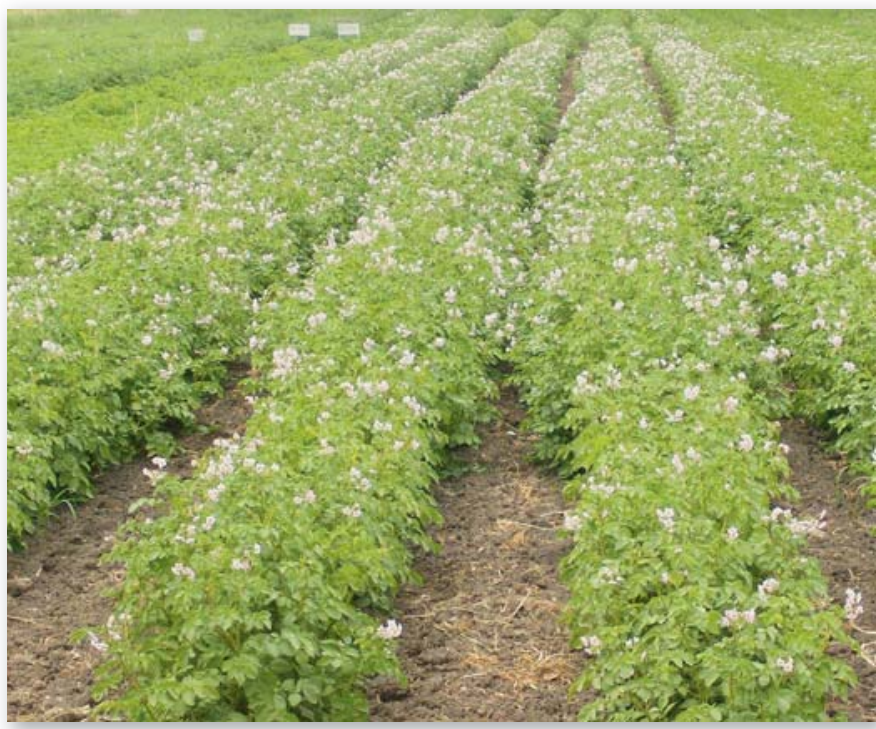

Рис. 1. Сорт картофеля Жанна в фазу цветения

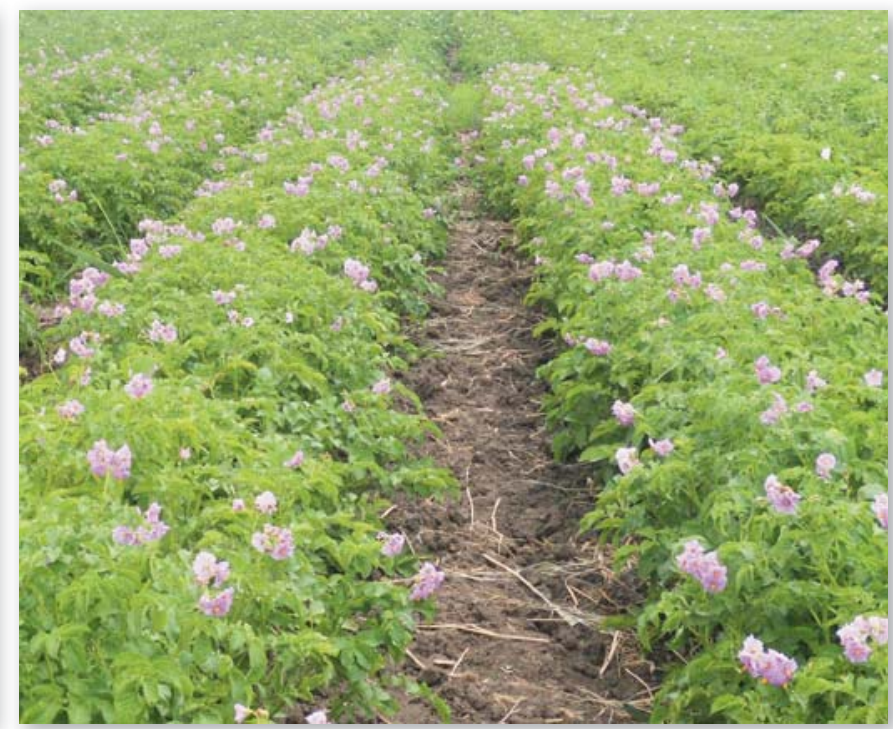

Рис. 2. Сорт картофеля Евгения в фазу цветения 
Таблица 1. Урожайность картофеля (т/га) при летних сроках посадки (среднее за 2014-2016 годы)

\begin{tabular}{|c|c|c|c|c|}
\hline Сорт (A) & $\begin{array}{c}\text { Густота } \\
\text { стояния, тыс. } \\
\text { раст/га (В) }\end{array}$ & $\begin{array}{c}1 \text { срок (III } \\
\text { декада июня) }\end{array}$ & $\begin{array}{c}2 \text { срок (III } \\
\text { декада июля) }\end{array}$ & $\begin{array}{c}3 \text { срок (I декада } \\
\text { августа) }\end{array}$ \\
\hline \multirow{2}{*}{ Вершининский } & 54,9 & 25,9 & 22,1 & 18,0 \\
\hline & 71,4 & 23,6 & 20,4 & 20,1 \\
\hline \multirow{2}{*}{ Жанна } & 54,9 & 31,8 & 32,8 & 22,2 \\
\hline & 71,4 & 31,2 & 29,7 & 24,0 \\
\hline \multirow{2}{*}{ Евгения } & 54,9 & 17,5 & 13,7 & 10,3 \\
\hline & 71,4 & 19,1 & 12,8 & 11,8 \\
\hline \multirow{2}{*}{$\begin{array}{l}\text { Волжанин - } \\
\text { контроль }\end{array}$} & 54,9 & 33,0 & 26,9 & 20,4 \\
\hline & 71,4 & 30,5 & 23,6 & 21,2 \\
\hline \multirow{2}{*}{ Валентина } & 54,9 & 37,5 & 31,8 & 23,6 \\
\hline & 71,4 & 33,0 & 30,0 & 25,7 \\
\hline \multirow{2}{*}{ Кисловодский } & 54,9 & 34,1 & 31,6 & 16,4 \\
\hline & 71,4 & 31,9 & 29,7 & 17,3 \\
\hline $\mathrm{HCP}_{05} \mathrm{~A}$ & - & 7,6 & 3,6 & 4,4 \\
\hline $\mathrm{HCP}_{05} \mathrm{~B}$ & - & $\mathrm{F} \phi<\mathrm{FT}$. & $\mathrm{F} \phi<\mathrm{F}_{\mathrm{T}}$. & $\mathrm{F} \phi<\mathrm{F}_{\mathrm{T}}$ \\
\hline
\end{tabular}

ем сорта Валентина (62,7-57,4\%) и Кисловодский, где полевая всхожесть была низкой в среднем до 33\%.

Полевая всхожесть картофеля второго срока посадки в целом была выше, так с густотой стояния 54,9 тыс. раст/га у сортов Вершининский, Жанна (рис. 1), Евгения (рис. 2) и Валентина она была от 9,6\% до 31,4\% больше аналогичных первого срока посадки. Растения сортов картофеля второго срока посадки с густотой стояния 71,4 тыс. раст/га отличались полевой всхожестью от первого срока с такой же густотой стояния. У сортов Вершининский (рис. 3) и Жанна она была выше на 3-5,1\%, у сорта Валентина этот показатель был значительно больше - 38,8\%. В то же время у сортов Волжанин и Евгения наблюдалось снижение полевой всхожести на 10,6-27,9\% соответственно тем же сортам первого срока посадки, но это в пределах ошибки опыта.

Полевая всхожесть картофеля третьего срока посадки была заметно ниже, чем на первых двух сроках. У сортов Жанна, Вершининский и Валентина полевая всхожесть составляла от 56,4 до 73,3\% при различной густоте стояния растений. Сорт Кисловодский показал низкую полевую всхожесть (32-40\%) при этом сроке посадки, поэтому третий срок посадки картофеля для региона не целесообразен.

Биометрические показатели высоты растений сортов картофеля первого срока посадки, высаженных с густотой 71,4 тыс. раст/ га $(1,40 \times 0,10$ м), были выше на $25 \%$, чем при густоте 54,9 тыс. раст/га $(1,40 \times 0,13$ м) аналогичных сортов. Это связано с тем, что при густоте стояния 71,4 тыс. раст/га растения взаимно затенялись, вследствие чего вытягивались в высоту. По количеству основных стеблей, листьев и массы ботвы наблюдалась обратная зависимость: увеличение показателей отмечено при посадке с меньшим загущением растений - 54,9 тыс. раст/га.

При втором сроке посадки высота растений с густотой стояния 71,4 тыс. раст/га была выше, чем при 54,9 тыс. раст/га и опережала сорта первого срока посадки. Биометрические показатели по количеству основных стеблей, листьев и массы ботвы так же, как и на первом сроке, были выше при густоте стояния 71,4 тыс. раст/ га, по сравнению с 54,9 тыс. раст/га и выше по всем сортам первого срока посадки.

Растения сортов картофеля третьего срока посадки независимо от густоты стояния уступали по биометрическим показателям первых сроков посадки: высота растений на (39\%; 9-41\%), количеству основных стеблей на (5-12\%; 5-45\%), по массе ботвы на $(7,5-11,5 \% ; 11,0-13,7 \%)$.

Таблица 2. Доля семенной фракции картофеля (\%) при летних сроках посадки (среднее за 2014-2016 годы)

\begin{tabular}{|c|c|c|c|c|}
\hline Сорт & Густота стояния, тыс. раст/га & 1 срок (III декада июня) & 2 срок (III декада июля) & 3 срок (I декада августа) \\
\hline \multirow{2}{*}{ Вершининский } & 54,9 & 47,4 & 66,2 & 45,1 \\
\hline & 71,4 & 62,1 & 61,7 & 50,8 \\
\hline \multirow{2}{*}{ Жанна } & 54,9 & 55,2 & 58,1 & 53,3 \\
\hline & 71,4 & 61,7 & 63,1 & 56,7 \\
\hline \multirow{2}{*}{ Евгения } & 54,9 & 67,1 & 80,0 & 53,4 \\
\hline & 71,4 & 56,3 & 83,5 & 55,8 \\
\hline \multirow{2}{*}{ Волжанин - контроль } & 54,9 & 48,0 & 46,4 & 46,6 \\
\hline & 71,4 & 48,0 & 58,4 & 48,1 \\
\hline \multirow{2}{*}{ Валентина } & 54,9 & 55,1 & 71,0 & 52,1 \\
\hline & 71,4 & 67,0 & 70,0 & 53,9 \\
\hline \multirow{2}{*}{ Кисловодский } & 54,9 & 56,9 & 60,3 & 53,0 \\
\hline & 71,4 & 53,7 & 61,2 & 54,6 \\
\hline
\end{tabular}




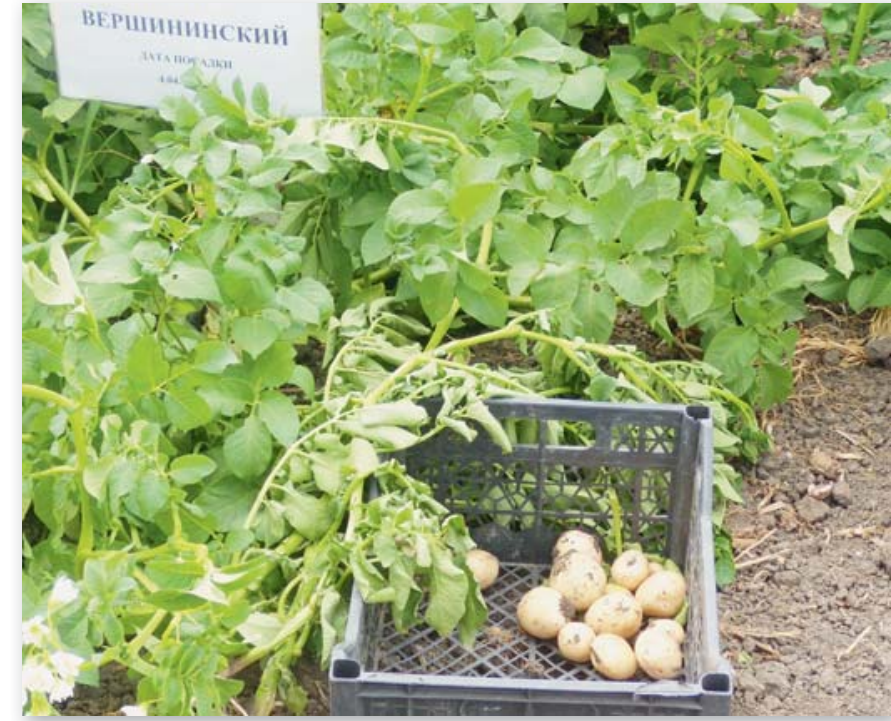

Рис. 3. Проведение пробной копки на сорте картофеля Вершининский

Сроки посадки повлияли не только на биометрические показатели во время вегетации, но и на урожайность картофеля.

Учет урожая показал, что под влиянием густоты стояния растений и срока посадки, урожайность по сортам была различной. Урожайность сортов картофеля при первом сроке посадки (III декада июня) была выше при густоте стояния 54,9 тыс. раст/га, а при втором сроке посадки - с размещением 71,4 тыс. раст/ га, за исключением сорта Евгения (табл. 1).

Наиболее заметная разница 5,7 т/га отмечена у сорта Валентина. У остальных сортов при первом сроке посадки разница между вариантами по урожайности, в зависимости от густоты посадки, составила 0,53,2 т/га. Урожайность сортов второго срока посадки была ниже первого срока, а разница между густотой стояния была на уровне 0,9-1,9 т/га.

Урожайность картофеля III срока посадки была заметно ниже, чем при первых двух сроках. Наиболее низкой урожайностью при этом сроке посадки выделялись сорта Евгения и Кисловодский (10,3-11,8; 16,417,3 т/га). Изменение густоты стояния растений с 54,9 тыс. раст/га до 71,4 тыс. раст/га не существенно не повлияло на выход клубней с одного растения. Товарность у большинства сортов была высокой - в пределах от 88,3 до 96,2\%. Отмечено небольшое увеличение товарных клубней при густоте посадки 54,9 тыс. раст/га $(1,40 \times 0,13$ м), по сравнению со схемой $1,40 \times 0,10$ м с густотой 71,4 тыс. раст/га. Сорт Волжанин при густоте стояния растений 71,4 тыс. раст/га в первый срок посадки характеризовался невысокой товарностью $64,6 \%$.

Выход средней фракции (масса клубня от 40 до 80 г), имеющей значение для получения семенного материала, был разным. Изменение густоты стояния не повлияло на этот показатель у сортов Волжанин и Кисловодский на первом сроке посадки. у сортов Вершининский, Валентина и Жанна, наоборот, выход семенной фракции был больше на 6,5-14,7\% при размещении 71,4 тыс. раст/га $(1,40 \times 0,10$ м), по сравнению с 54,9 тыс. раст/га (табл. 2).

На увеличенный выход семенной (средней) фракции клубней у большинства сортов второго срока посадки повлияла густота стояния 71,4 тыс. раст/га, только у сорта Вершининский выход семенной (средней) фракции клубней был меньше на густоте посадки 71,4 тыс. раст/га, по сравнению с густотой 54,9 тыс. раст/га. При третьем сроке посадки выход семенной фракции у всех сортов уступал первым двум срокам посадки.

Заключение. Для получения семенного картофеля лучший срок посадки в условиях дельты Волги - III декада июля, кроме сорта Евгения. При третьем сроке посадки (I декада августа) отмечена низкая урожайность на всех сортах, клубни имели тонкую, легко повреждающуюся кожуру и не были готовы к хранению.

Густота стояния растений решающим образом повлияла на выход семенной фракции клубней картофеля всех сортов, за исключением сорта Евгения. Сорта Кисловодский и Вершининский обеспечивали наибольший выход семенной фракции клубней при густоте стояния 71,4 тыс. раст/га $(1,40 \times 0,10$ м). При возделывании картофеля сортов Валентина, Жанна и Волжанин для получения семенного материала в условиях дельты Волги лучшей густотой стояния являлась 54,9 тыс. раст/га $(1,40 \times 0,13 \mathrm{~m})$.

\section{Библиографический список}

1.Байрамбеков Ш.Б., Коринец В.В., Валеева З.Б., Дубровин Н.К. и др. Технология производства картофеля в Астраханской области: рекомендации Астрахань: ООО Новая линия, 2007. 104 с.

2.Доспехов Б.А. Методика полевого опыта. М.: Агропромиздат, 1985. 351 с.

3.Методические указания по учету и контролю важнейших показателей процессов фотосинтетической деятельности растений в посевах. М.: ВАСХНИЛ, 1969. 43 с. 4.Методика полевого опыта в овощеводстве и бахчеводстве. Под ред. В.Ф. Белика, Г.Л. Бондаренко. М.: ниИОХ, 1979. 210 с.

5.Методика исследований по культуре картофеля. М.: НИИКХ, 1967. 131 с

\section{Об авторах \\ Дубровин Николай \\ Константинович, доктор с. $-x$}

наук, в.н.с. отдела агротехнологий и мелиораций

Боева Тамара Васильевна, кандидат с. - х. наук, с.н.с. отдела агротехнологий и мелиораций

\section{Киселева Галина Николаевна,}

м.н.с. отдела агротехнологий и мелиораций

Всероссийский научно-исследовательский институт орошаемого овощеводства и бахчеводства - филиал ФГБНУ «Прикаспийский аграрный федеральный научный центр Российской академии наук». E-mail: vniiob@mail.ru

Seed potato under summer planting N.K. Dubrovin, DSc, leading research fellow, department of agrarian technologies and land reclamation

T.B. Boeva, PhD, senior research fellow, department of agrarian technologies and land reclamation

G.N. Kiseleva, junior research fellow, department of agrarian technologies and land reclamation

All-Russian Research Institute of Irrigated Vegetable and Watermelon Growing - the branch of FSBSI «Near-Caspian Agrarian Federal Scientific Centre of Russian

Academy of Sciences».

\section{E-mail:vniiob@mail.ru}

Summary. Determining of the best summer planting time for obtaining the largest number of potato tubers of seed fraction with weight from 40 to $80 \mathrm{~g}$ is one of the main tasks of potato seed growing in the Volga delta, since the spring planting is not suitable for potato seed production. The researches were conducted with six domestic prospective varieties: Vershininskiy, Zhanna, Evgenia, Valentina, Kislovodskiy and Volzhanin, taken as a control variant. On the basis of our research, for the first time it was established the optimum summer planting time of potato - the third decade of July with plant density from 54,9 to $71,4 \mathrm{t} / \mathrm{ha}$, ensuring the production of high-quality seed material.

Keywords: potatoes, planting time, plant population, varieties, seed fraction. 